\title{
Worker mobility under attack? Explaining labour market chauvinism in the EU
}

Maurizio Ferrera \& Alessandro Pellegata (University of Milan)

\begin{abstract}
The aim of this paper is to investigate citizen views on the free movement of workers within the European Union (EU). We are interested in how situational and relational factors affect labour market chauvinist attitudes. Drawing on the threat theory, we advance new hypotheses on the role of intertemporal relative deprivation in amplifying chauvinist inclinations. From the intergroup contact theory and transnational approaches, we borrow insights on the role played by cross-border experiences and inclusion in discursive and associational networks in containing chauvinism. The analysis uses the original 'Reconciling Economic and Social Europe' (REScEU) survey conducted in six EU countries (i.e., France, Germany, Italy, Poland, Spain and Sweden) in the fall of 2016. The article shows that - though rooted in class and status positions - chauvinist attitudes are clearly sensitive to contingent situations and lifeworld experiences.
\end{abstract}

Keywords: Chauvinism; European Union; free movement; immigration; labour market; public opinion. 


\section{Introduction}

In the early 1990s, a brave judge of the European Court of Justice (ECJ), Francis Jacobs, stated in a ruling that European Union (EU) law confers to the free movers' inviolable subjective rights to equality of treatment and non-discrimination as 'human beings, entitled to live in any EU Member State in freedom and dignity' (Jacobs 1992). The ruling came a few months after the signature of the Treaty of Maastricht in February 1992, which established EU citizenship. Since then, 16 new countries have joined the EU and three new Treaties have come into effect: Amsterdam (1999), Nice (2003) and Lisbon (2009). The latter reiterated the rights of free movement of persons. However, such rights are now increasingly contested. Access to domestic labour markets and social benefits by non-nationals, even if they belong to the EU, is visibly under attack (Baute et al. 2018; Kramer et al. 2018). In the wake of rising inflows from the newly acceded Member States, segments of political elites and public opinions of receiving countries have developed increasing hostility against immigrants, held responsible for social dumping dynamics in terms of jobs and wages as well as for 'benefit tourism’ (Heindlmaier and Blauberger 2017; Schmidt et al. 2018).

This paper aims at investigating individual attitudes towards the intra-EU mobility of workers. In particular, we are interested in those pathways that generate support for exclusionary practices or 'labour market chauvinism' (hereinafter referred to as chauvinism), that is, the idea that nationals should have priority in accessing available jobs. Variants of the intergroup threat theory postulate that individuals with a socio-economic status that makes them more vulnerable are more likely to express anti-immigration attitudes and support exclusionary measures (Riek et al. 2006; Kriesi et al. 2008; 2012; Mewes and Mau 2012). Building on these theories, we make a step forward by analysing the role played by general political orientations as well as situational and relational factors often neglected in the literature. More precisely, we hypothesise that, controlling for individual socio-economic 
('structural') positions, right-wing ideological preferences and situations of inter-temporal relative deprivation are positively associated with chauvinism. By contrast - in line with the intergroup contact theory (Pettigrew 1998; 2016) and transnational approaches (Mau 2010; Kuhn 2015) - we expect that citizens who support the EU, travel across European countries, share opinions about the EU with others and belong to trade unions are less prone to support exclusionary measures. We test our research hypotheses on a sample of six EU Member States - France, Germany, Italy, Poland, Spain and Sweden - using data from the original 'Reconciling Economic and Social Europe’ (REScEU) survey, 'Citizen views on Solidarity and Integration', conducted in autumn 2016 (Ferrera and Pellegata 2017). Empirical results demonstrate that the association between chauvinism and structural positions varies across countries, revealing the influence of macro-level features. However, if we isolate microsituational and relational factors - keeping structural positions under control - individual experiences and contingent situations tend to be strongly associated with chauvinist attitudes.

First, our study contributes to the existing literature in both analytical and empirical terms. To our knowledge, our work is the first attempt to assess the role played by situational and relational factors - intertemporal experiences of economic deprivation, concrete experiences of transnational contacts and inclusion in discursive and associational networks on preferences towards worker mobility. Second, we investigate how the relation between chauvinism and structural positions, situational and relational factors vary across a sample of countries that present different political, economic and social characteristics. Third, our original data reveal attitudes after those developments - the great recession and the euro crisis, the refugee crisis, terrorist attacks and Brexit - that have dramatically changed the European political landscape.

The paper is structured as follows. The next section summarises the state of the art. The third section presents the general theoretical framework that guides our analyses and 
generates our research hypotheses. The fourth section describes data and methods, while the fifth section discusses our empirical findings. Finally, the last section concludes and draws some policy implications.

\section{External threats and chauvinist attitudes: state of the art}

The view that non-nationals should have 'less eligibility' - weaker or no rights of access - to the employment opportunities and welfare benefits of the hosting country has been often associated with the concept of chauvinism (Kitschelt 1997; Svallfors 2012). Research on labour market or welfare chauvinism has mainly drawn on some variant of the intergroup threat theory' (Stephan et al. 2009). According to the latter, the perception of a potential 'realistic' (tangible) or 'symbolic' (intangible) harm from outsiders activates negative emotions and antagonistic behaviours on the side of individuals or collective actors that identify themselves as insiders or 'ingroup'.

Realistic threats tend to prompt a utilitarian calculus: immigrants are considered as dangerous competitors in a zero-sum game for key but scarce opportunities (jobs) and resources (welfare). The anticipation of possible material losses triggers off insecurity, frustration, fear or even anger against immigrants and strong preferences for closure. The relationship between realistic threats based on resource competition and self-interest, on one hand, and chauvinism, on the other, has been investigated by a wealth of empirical studies, using a wide variety of designs and measurements. Scholars disagree on the cumulative direction of this strand of research, but the overall assessment is that the explanations based on self-interest have not fared well so far (e.g., Mewes and Mau 2012; Hainmueller and Hopkins 2014; Berg 2015). The main problem seems to lie in contrasting and, at times, ambiguous conceptualisations as well as in the difficulty of nailing down empirically actual dynamics of zero-sum competition fuelling negative attitudes (Pottie-Sherman and Wilkes 
2017).

Symbolic threats affect intangible goods, such as cultural identity, traditions and habits, which are upheld by deep and often latent values and emotions. Immigrants are seen as a disturbing outgroup and become the target of moral evaluations, negative stereotyping and even cultural contempt (Hjort 2016). This leads, in turn, to an inflated sense of moral legitimacy of the in-group interests, culture and entitlements and, conversely, the attribution of a fictitious homogeneity in terms of (negatively evaluated) cultural traits, motives and conduct to the outgroup. The result is an amplification of perceived intergroup differences and a greater potential for aggressive and antagonistic behaviours. Symbolic threats activate chauvinist attitudes through socio-psychological dynamics involving feelings, emotionally charged beliefs and subtle forms of prejudices.

The literature has identified various pathways that activate such dynamics and has highlighted, in particular, the facilitating or triggering role of authoritarian orientations, political ideologies and party cues, in the context of 'symbolic politics' (McLaren and Johnson 2007; Mewes and Mau 2012; Pettigrew 2016). Some scholars have introduced the idea of a new 'integration-demarcation' divide in Europe, juxtaposing supporters of 'opening' and intra-EU mobility against supporters of 'closure' and anti-immigrant chauvinism. While partly linked to self-interest, this new divide rests on cultural fears and symbolic political dynamics, linked to right-wing populism (Kriesi et al. 2008; 2012; Teney et al. 2014).

Overall, the cultural perspective has been more consistently tested and corroborated than the resource competition perspective (Houtman 2003; van Oorschot 2007; van der Waal et al. 2010; Mewes and Mau 2012; Reeskens and van Oorschot 2012). However, while some studies indicate that cultural explanations of chauvinism seem to trump approaches based on self-interest (van der Waal et al. 2010), other studies show that there are no empirical reasons to disregard economic factors in explaining chauvinism (Mewes and Mau 2012). 
In order to move beyond the rather inconclusive contest between economic and cultural approaches, a new trend of research has been recently shifting the focus of analysis. Mainstream research has primarily concentrated on pathways generating anti-immigrant attitudes, captured in aggregate distributions and social categories primarily defined by occupation and education within national communities as a whole. However, recent studies stress that conventional measures of class, education and income are of limited use in understanding the role of risk, insecurity and precariousness and suggest taking into consideration not only 'objective' conditions but also subjective perceptions and expectations (Mewes and Mau 2012; Teney et al. 2014).

This new research strand also brings into the picture experiential and relational factors. Drawing on the intergroup contact theory - originally elaborated by Allport (1954) - what is expected is that concrete contacts between individuals and groups have positive effects in reducing prejudice, diffidence and antagonism. One key underlying mechanism is named 'self-expansion': interactions encourage people to integrate new things into their own minds and lives (Aron et al. 1998). As shown by recent research, this broadening of horizons contains negative opinions and fosters more benign attitudes towards outsiders (Dixon 2006; Laurence 2014; Pettigrew 2016; Cappelen and Peters 2017).

In addition, combining contact and network theory, a number of studies have highlighted the way in which individual attitudes - including chauvinism - can be shaped and reshaped by inclusion in associational and discursive circles (Berg 2009). In a similar vein, other authors have shown the importance of 'transnationalism' in tempering pro-closure preferences (e.g., Kuhn 2015).

Analysing situational and relational variables that impinge on attitude formation at the individual level is a complex task, not least because such variables are not typically observed and measured by mainstream surveys. In this paper, we make some steps in this direction by 
using an original survey that has deliberately tapped into some experiences and situations directly lived by respondents.

\section{Explanatory model and research hypotheses}

Individuals are always located within a social macro-hierarchy of resources, opportunities, privileges and powers that shape their objective life chances and subjective orientations. Such shaping is not deterministic and takes place in the reality of lived experiences. The inevitable influence of class and status is enacted by this micro-situational reality. As aptly suggested by Collins (2000: 18), micro-situations are 'the ground zero of all social action ... Nothing has reality unless it is manifested in a situation somewhere'. Individuals order the flow of everyday life into more or less extended temporal moments in which relationships, preferences, emotions, resources and opportunities are organised by attributing to them a relatively coherent subjective meaning. Situations are, thus, pervaded by a distinctive psychological climate, that is, a mental representation of proximal environments in their dynamic and concrete unfolding (Rauthmann et al. 2017).

While always important from a general theoretical perspective, experiences and situations have become ever more salient for attitude formation in the wake of incisive social and economic transformations. As a matter of fact, the role played by categorical memberships as stable sources of identity has been constantly declining in the last decades; the momentum of contemporary life is increasingly grounded in the flow of temporally and locally situated proximity contexts. Resting on these broad assumptions, our theoretical framework identifies four different sets of explanatory factors that affect the formation of chauvinist attitudes. We present them from the more distal to the more proximal ones in relation to chauvinist attitudes.

Structural Positions. These are the traditional background variables prevailing in 
attitudinal studies. Structural positions are what anchors individuals to the social macrohierarchy. Occupation, income, education, gender and age are the typical 'anchors', in terms of class as well as status. Positions generate structural inequalities and power differentials, which, in turn, produce antagonistic potentials in terms of attitudes and behaviours.

General political orientations. These are the basic traits of people's political culture and have to do with feelings of political trust and efficacy, party identification, core ideological leanings, a propensity to be politically active or passive and so on. These types of orientations and relations are loosely rooted in positions (through position-specific socialisation mechanisms), but - ceteris paribus - may change over time based on experiences. General political orientations and relations provide important symbolic, emotional, relational and organisational resources for pursuing one’s ends within macro-, meso- and micro-societal hierarchies.

Situations. The conflict potential linked to positions and general political orientations and relations is actualised in the context of contingent (i.e., uncertain, often fortuitous) situations. These depend on specific features (including mere chance) and events during the life cycle. Situations have both an objective dimension (i.e., what actually happens) and a subjective one (i.e., how the experience is lived, perceived and evaluated). Situations may be lived in isolation but are typically shared with other people.

Inclusions. Experiential and situational sharing is important because it affects the formation of group perceptions, beliefs, emotions, habits and interests. In this respect, situations are sensitive to ‘inclusion’ factors: being inserted in associational and discursive networks can make a difference, even keeping all previous factors as constant.

In the context of our topic, the framework works out in the following way. An increase of intra-EU mobile workers poses a potential threat. The actual perception of threat is linked, in the first place, to structural positions. Here, we rest on the theoretical propositions of 
mainstream research, according to which threats are greater for low-skilled and low-educated people - the so-called 'losers of globalization' - who occupy more vulnerable positions in the labour market and have lower cognitive skills (Kriesi et al. 2008).

HP1: Low-skilled workers and low-educated people are more prone to express chauvinist attitudes (loser hypothesis).

The threat potential posed by mobile workers is subjectively processed through general political orientations, in particular, basic ideological leanings, cultural and social openness, support for integration as such (Kriesi et al. 2008; 2012; de Koster et al. 2013). In line with the literature, we expect a strong link between, on the one hand, right-wing leanings (typically associated with preferences for closure), and low diffuse support for European integration (including free movement and non-discrimination principles) and labour market chauvinism, on the other hand. Therefore:

HP2a: Controlling for structural positions, right-wing ideological preferences are positively associated with chauvinist attitudes (ideological preferences hypothesis).

HP2b: Controlling for structural positions, support for the integration process is negatively associated with chauvinist attitudes (diffuse support hypothesis).

The main novelty that we want to bring into the analysis is a focus on those situational and relational dynamics which mould the overall ideational 'sense' attributed to material and symbolic threats. Here, we focus in particular on three dynamics and factors that are rooted in people's lifeworlds. The first dynamic is the experience of intertemporal relative deprivation a contingent increase of economic hardship - as a potential trigger of chauvinism. Such effect 
is likely to have increased in the wake of the great recession, which has pushed into relative deprivation members of the middle class, who are not in direct competition with migrant workers.

HP3: Controlling for structural positions, individuals experiencing a relative intertemporal deprivation are more prone to express chauvinist attitudes (relative deprivation hypothesis).

The second factor has to do with the degree of familiarity and of actual interactions with outsiders in containing chauvinism (Dixon 2006; Pettigrew 2016). Building on transnational approaches, we expect that people who have actually experienced contacts with citizens living in other European countries are more likely to support the free movement principle and, therefore, less likely to back exclusionary measures against mobile workers. As has been aptly argued by Recchi (2015), this group is much larger than the sum of EUnationals who find themselves in a given Member State in a particular time, as it also includes those who moved in earlier times. In order to better contextualise the general concept of 'transnationalism' for our purposes, we define all those who have taken advantage, at some point, of free movement as 'EU-politans'.

HP4: Controlling for structural positions, individuals with trans-EU experiences are less prone to express chauvinist attitudes (EU-politanism hypothesis).

A third factor is the degree to which citizens share their opinions and life experiences with others. We expect that people's inclusion in discursive networks, where the EU and EUrelated matters are debated, might contribute to dilute fear and anxieties about threats. We also expect that belonging to a professional or trade union association may help individuals in 
coping with the challenge of economic competition and orient them towards accepting and integrating non-national workers and, thus, contrast the adoption of exclusionary practices (Marino et al. 2015).

HP5a: Controlling for structural positions, individuals who are included in discursive networks are less prone to express chauvinist attitudes (discursive networks hypothesis).

HP5b: Controlling for structural positions, trade unions members are less prone to express chauvinist attitudes (associational networks hypothesis).

\section{Data and methods}

We performed our empirical analyses using the 2016 REScEU Mass survey (Ferrera and Pellegata 2017). This dataset includes more than 8,000 individual observations collected in six EU Member States: France, Germany, Italy, Poland, Spain and Sweden. ${ }^{1}$ These countries present important differences that may impinge on both the type and intensity of threats and on subjective reactions. They have different labour markets, productive structures and welfare states. Some of them have been more severely hit by the crisis (i.e., Italy and Spain) than others. There are also important variations for what concerns the presence of right-wing populist parties (i.e., France, Italy, Poland and Sweden) that campaign on nativist issues and exclusionary measures. Finally, the sample countries have experienced different types and intensities of migration flows and vary in the share of non-native workers residing on their territory. France, Germany and Sweden have long been receiving countries; Italy and Spain have only recently turned from emigration to immigration countries, while Poland is the largest sending country within the EU.

The dependent variable used in the empirical analysis is operationalised through a survey item that measures individual attitudes towards the access of citizens coming from 
other EU Member States into national labour markets. The question reads as follows:

According to the EU law, EU citizens are allowed to work in every member state. How do you think EU citizens of other nationalities that come to work in our country should access the labour market? (1) Freely and individually, just like me and my national fellows; (2) As guest workers and only as long as they keep the job that let them in [COUNTRY]; (3) [NATIONALITY] workers should have priority access to jobs and employment services.

The three response categories contrast the status quo, resting on free movement and 'nondiscrimination' (option 1), with a second position resting on a logic of 'hospitality' (option 2) as well with a third 'nativist' position (option 3) (Ferrera 2016). Table A1 in the Appendix presents the country-level distributions of responses along the three categories of the dependent variable.

In five of the six countries, the largest share of respondents opted for a full openness of the national labour market (i.e., 49 per cent of the entire sample). As expected, in Poland a country with high outward mobility flows - there is a significant absolute majority in favour of openness (59 per cent). Also, in Germany, the absolute majority supports this option (51 per cent). Given the long-standing tradition of admitting foreign migrants as Gastarbeiter, Germany also displays the highest share of respondents in favour of an access conditional to the presence of a work contract (27 per cent). In Italy (47 per cent), Spain (49 per cent) and Sweden (49 per cent) openness is still supported by a plurality of respondents. There are, however, quite sizeable groups in favour of the conditionality option and the chauvinist one. France stands out: the relative majority of respondents (45.6 per cent) supported chauvinism. In France, the share of pro-openness respondents is the sample’s lowest. 
We now briefly illustrate the main predictors of welfare chauvinist attitudes, referring to the Online Appendix for a more detailed description. Following our theoretical framework, we measure structural positions with two main variables: occupational status and education level. General political orientations are measured through two scales commonly used by the literature. Ideological leanings are captured through respondents' left-right self-placement. Orientations on the new integration-demarcation conflict line (Kriesi et al. 2012) are tapped through respondents' self-placement on a scale delimited by two extremes: 'integration has gone too far’ versus 'integration should be strengthened’.

Situations of inter-temporal relative deprivation are measured through respondents' retrospective evaluation of their household financial situation in the previous five years. We operationalise EU-politanism - that is, familiarity with other EU places and contexts - by asking respondents if they have ever visited another EU country for work, study or leisure. The inclusion in discursive networks builds on an item asking respondents if they speak with their relatives and friends about the Euro and other EU-related issues. Inclusion in associational networks is captured through trade unions' membership of respondents or another member in the household.

Given the nominal nature of the dependent variable, we employed multinomial logistic regression models with robust standard errors. The first response category of the dependent variable ('freely and immediately') serves as a reference category. In our analysis, we are interested in which factors affect the predicted probability that respondents opted for the closure of the labour market by giving priority access to nationals (option 3) instead of a complete openness. ${ }^{2}$ Considering the potential country-level confounders, which would be very hard to control for and that the precise definition of some covariates is different across countries, we decided to split the sample and run regression analyses separately in each country, rather than pooling the data from the six countries. The small number of upper-level 
units considered in our study - six countries - does not allow us to adopt a multilevel modelling technique with random intercepts and random slopes to take into account crosscountry differences appropriately (Maas and Hox 2005).

\section{Findings}

Tables A2-A7 in the Appendix illustrate the results of our regression analyses of the dependent variable - attitudes towards the EU migrant workers' access to domestic labour markets - on the covariates in each sample country. As already said, for reasons of clarity, we discuss results for the response category referred to as the chauvinist position: 'nationals should have priority access to the labour market'. According to our analytical model and given the interrelations between the independent variables, we have defined six different model specifications. Every model tests the association between labour market chauvinism and one specific set of independent variables, defined by the hypotheses advanced above. This empirical strategy allows us to disentangle the net statistical effect played by each set of independent variables, avoiding concerns for multicollinearity and controlling only for structural antecedents - age, gender, occupation and education - that might be the source of spuriousness.

Given the non-linear nature of the multinomial logistic models, regression coefficients reported in Tables A2-A7 do not provide a meaningful and straightforward interpretation of substantive empirical results. To capture the strength and the significance level of the association between chauvinism and the key covariates, we computed the predicted probabilities of respondents to support exclusionary measures at changing values of the different independent variables. Figure 1 displays six graphs - one for each sample country plotting the changes in the predicted probability of labour market chauvinism, according to the discrete change in the categories of the variables measuring respondents' structural 
positions.

[Insert Figure 1 about here]

Plots in Figure 1 show that the association between chauvinism and structural positions does not follow the same patterns in the six countries studied. With regard to occupation, in France and Germany, those categories that are more vulnerable to the threat coming from the competition with other EU workers - service and production workers as well as the unemployed - do not show a significantly higher predicted probability to opt for exclusionary measures than the salaried middle class. In these two countries, however, the likelihood of high-skilled professionals employed in socio-cultural sectors - those who are expected to be less vulnerable - to express chauvinism is significantly lower than white collars. In the other four countries, by contrast and as expected, individuals more exposed to the threat coming from workers of other EU Member States have a higher-predicted probability to express chauvinist attitudes.

Empirical results, however, show important cross-country differences. In Spain and Sweden, only service and production workers are significantly more prone to support exclusionary measures than white collars; while in Italy and Poland, only the unemployed show a significantly higher predicted probability to express chauvinist positions. Interestingly, Sweden is the only country in which welfare recipients - pensioners and people receiving welfare subsidies - are more prone to support chauvinism than the salaried middle class. This may be related to the universalistic character of the Swedish welfare state, which grants to any resident access to benefits, regardless of contributions.

Regarding education, apart for Poland and Sweden, people who have obtained tertiary education or more are significantly less prone to express chauvinist attitudes than low- 
educated respondents are. ${ }^{3}$ In Italy and Spain, also, the ‘upper secondary education' category presents a significantly lower-predicted probability to support labour market closure than the 'lower secondary education or less’ category.

Considering that only in some of the sample countries occupational vulnerability and high education are simultaneously and significantly linked to labour market chauvinism, HP1 finds only partial empirical support in our data. However, we have run a further empirical check of HP1. Individual structural vulnerability is determined by a combination of the skills linked to their occupation, the strength of the competition with migrant workers given by the sector in which they are employed and the cultural capital given by their educational attainment. Thus, we have isolated those individuals that, presenting specific characteristics, should be more exposed to material and symbolic threats: low educated citizens, unemployed or service and production workers occupied in the private sector of three fields particularly vulnerable to the competition with migrants (i.e., construction and buildings, transports and logistics and retail and wholesale). In Table A8 in the Appendix, we have substituted occupation and education with this new dummy variable that measures the exposure to threat and we have compared the difference in the predicted probability of expressing chauvinist attitudes between exposed and non-exposed citizens, controlling for age and gender. Figure A1 (see Appendix) shows that, with the exclusion of Poland, citizens who are more vulnerable to the material and symbolic threats generated by the free movement of EU workers are significantly more prone to express chauvinist attitudes.

Models 2-6 in Tables A2-A7 show that in most of the countries variables measuring general political orientations, relative intertemporal deprivation, EU-politanism, and inclusion in discursive as well as associational networks are strongly and significantly associated to chauvinist attitudes. Furthermore, values of the Wald tests, reported at the bottom of these models, show that - in most of the cases - models also including orientations or situational or 
relational factors have the highest goodness of fit to our data than Model 1, including only structural positions. Figure 2 plots one graph for each sample country displaying the difference in the predicted probability of expressing chauvinist attitudes for a one-unit change in the scales measuring left-right preferences and EU support, respectively.

[Insert Figure 2 about here]

For both explanatory factors - all else being equal - the relationship between chauvinism and general political orientations is significant in all the six countries studied. These results lend strong support on both HP2a and HP2b. Moving from left to right on the traditional ideological continuum, results in a higher-predicted probability express chauvinist attitudes. At the same time, the more a respondent believes that the integration process should be strengthened, the lower the predicted probability of labour market chauvinism. In France, Germany and Italy, the effect of both variables on chauvinism is particularly strong, while the effect is weaker in Poland and Spain. Especially in Poland, this result could be partially explained by the high emigration rates of workers. In Sweden, opinions about the integration process outperform left-right preferences in terms of the magnitude of the effect on labour market chauvinism. These results confirm the important role played by political orientations in part already highlighted by the literature (e.g., Karreth et al. 2015). Our analysis adds, however, an important specification: political orientations on both the traditional ideological spectrum and the new integration-demarcation dimension are strongly associated, not only to attitudes towards immigration in general but also to citizens' opinions on the intra-EU mobility of workers.

The six graphs, plotted in Figure 3, show the difference in the predicted probabilities of opting for the chauvinist category of the dependent variable at changing values of the 
independent variable, measuring respondents' intertemporal deprivation. Those who have declared that their household financial situation stayed about the same, during the previous five years, are taken as a reference, and we have computed the difference in the predicted probability to express chauvinist attitudes for those who think that their situation got worse and for those who believe that it has improved.

[Insert Figure 3 about here]

Our results confirm HP3 in four out of six countries. In France, Germany and Italy, respondents who have declared that their household financial situation got worse in the previous five years present a significantly higher predicted probability of supporting exclusionary measures than those who consider their situation as stable. In Sweden, this association is statistically significant only at a $90 \%$ confidence level, but the opposite situation is confirmed: for individuals that have experienced an improvement, the predicted probability of expressing chauvinist attitudes is lower than those whose situation stayed about the same. In Poland and Spain, instead, the association between relative deprivation and chauvinism is not confirmed. A potential explanation for this result could be that the increase of economic hardship has affected, in particular, specific categories of individuals in Poland and Spain. Thus, occupational classes capture the relationship between chauvinism and relative deprivation. In these two countries, in fact, service and production workers or the unemployed are significantly more prone to express chauvinist attitudes than the salaried middle class.

Finally, Figure 4 plots three graphs displaying the predicted probabilities of expressing chauvinist attitudes at changing values of three dichotomous variables: EU-politanism (left), inclusion in discursive networks (centre) and trade unions membership (right). 
[Insert Figure 4 about here]

Results reported in the graph on the left of Figure 4 confirm HP4 in four out of six countries. In Germany, Italy, Spain and Sweden, 'EU-politanism' (as defined above) is negatively and significantly associated with chauvinism. In these countries, even controlling for the effects of structural positions, individuals with 'EU-politan' experiences present a lower-predicted probability of chauvinism. Conversely, those who have never had such experiences are more likely to be chauvinist. The association between EU-politanism and chauvinism is particularly strong in Sweden (-15 points), the sample country with the highest share of respondents who have visited another EU country (79\%). Unfortunately, our survey does not allow us to operationalise the concept of EU-politanism in an appropriate way. Kuhn (2015) builds a more fine-grained indicator of transnationalism, a concept very close to our idea of EU-politanism. By means of this indicator and its different sub-dimensions, Kuhn (2015: 94-100) demonstrates that Poland and France are two of the EU Member States that show the lowest aggregate levels of transnationalism. This result might contribute to explain the lack of significance in the relationship between chauvinism and EU-politanism in these two countries.

Our data confirm HP5a in all the countries analysed (see graph in the centre of Figure 4). On average, the predicted probability to support exclusionary measures of those who usually discuss with relatives and friends about EU-related issues is significantly lower (-6 points) than the probability of those who do not. Regardless of the country of residence and controlling for occupation and education, being included in discursive networks reduces chauvinism.

Finally, the graph on the right of Figure 4 shows that trade union membership contains 
chauvinist attitudes (HP5b), only in Italy and Spain. In these two countries, irrespective of occupation and education, belonging to trade unions is negatively and significantly associated to chauvinism. EU trade unions have generally supported worker mobility. Presenting an articulated 'Labour Mobility package' in 2016, the European Trade Unions Confederation (ETUC) stated in clear letters that 'The ETUC stands for free and fair mobility for all'. However, the saliency of mobility issues, the tones of their discourse, the extent to which national trade unions engage with the challenge of non-discrimination based on nationality varies a lot across countries (Marino et al. 2015). South European trade unions (including, to a lesser extent, the French trade unions) is known for its strong pro-immigration stance and its discursive and policy activism. The factors that account for the high significance of trade union membership in Spain and Italy is rooted in historical features and traditions: a long experience with emigration, past experience of transnational mobilisation in defence of their own compatriot workers abroad, the ideological tradition of 'internationalism' as well as the ambition to be general interest organisations and participate in overall policy making (Martínez-Lucio et al. 2013).

\section{Conclusion}

This article has investigated public attitudes towards mobile workers in six countries: France, Germany, Italy, Poland, Spain and Sweden. Drawing on the threat theory, intergroup contact theory and transnational perspectives, we have moved beyond the mainstream 'globalization loser hypotheses' by looking at a number of 'situational' and 'relational' factors. In particular, we have tested, on the one hand, the role of contingent experiences of intertemporal relative deprivation in possibly amplifying pro-closure sentiments and, on the other hand, the role of cross-border experiences and inclusion in discursive and associational networks in possibly containing chauvinism. Our empirical findings have confirmed our hypotheses in most of our 
countries.

Compared to the existing literature, our study highlights important cross-country differences for what concerns the antecedents of chauvinism. Country characteristics do affect the relationship between chauvinism and socio-economic status, contingent experiences of relative deprivation and interpersonal relations. Second, country-level differences impinge, in particular, on the association between chauvinism and structural positions. Low skills and low education are not associated to chauvinism in all the countries included in our study. Finally, orientations, situational and relational factors - our specific and novel focus - are significantly associated with chauvinism in most of the countries studied. Controlling for structural vulnerability, these factors contribute to explain the (de)activation of chauvinist attitudes. Ideological preferences and sharing opinions about the EU with others are significant predictors in all the sample countries. 'EU-politanism' displays a particularly strong negative association with chauvinism. In Southern EU Member States (i.e., Italy and Spain), moreover, trade unions’ members are less prone to support exclusionary measures.

What general implications can be drawn from our findings? Pro-closure attitudes constitute an alarming destabilising factor for the integration process. The role played by situational and relational factors indicate that the lure of souverainisme can be resisted, provided certain contextual conditions obtain. While structural positions are hard to modify, experiences and their perceptions are more amenable to the influence of specific anticipatory or compensatory measures. In its turn, fostering greater knowledge of the EU as such and its Member States ('EU-politanism') could reduce anxieties and fears about 'others'. It remains to be seen whether policy makers - especially political leaders - will be willing and able to exploit this potential in order to contain pro-closure sentiments and their destabilising effects. 


\section{Biographical notes}

Maurizio Ferrera is professor of Political Science at the University of Milan and principal investigator of the ERC-funded project, 'Reconciling Economic and Social Europe' (REScEU) (https://orcid.org/0000-0003-0869-2593). Alessandro Pellegata is a Research Fellow at the University of Milan, engaged in the REScEU project (https://orcid.org/00000003-0913-7938).

\section{Address for correspondence}

Alessandro Pellegata, Department of Social and Political Sciences, University of Milan, Via Conservatorio 7, 20122, Milan. Email: alessandro.pellegata@unimi.it.

\section{Acknowledgements}

This essay is part of the research project titled 'Reconciling Economic and Social Europe: The Role of Values, Ideas and Politics’, funded by an Advanced Grant of the European Research Council (Grant no 340534, P.I. Maurizio Ferrera).

\section{References}

Allport, G.W. (1954) The Nature of Prejudice, Reading: Addison-Wesley.

Aron, A., Norman, C.C. and Aron, E.N. (1998) 'The self-expansion model and motivation', Representative Research In Social Psychology 22: 1-13.

Baute, S., Meuleman B., Abts K. and M. Swyngendow (2018) 'European integration as a threat to social security: Another source of Euroscepticism?', European Union Politics, doi: 10.1177/1465116517749769.

Berg, J.A. (2009) '“Core networks and whites’ attitudes toward immigrants and immigration 
policy’, Public Opinion Quarterly 73(1): 7-31.

Berg, J.A. (2015) 'Explaining attitudes toward immigrants and immigration policy: A review of the theoretical literature', Sociology Compass 9(1): 23-34.

Cappelen, C. and Peters, Y. (2017) 'The impact of intra-EU migration on welfare chauvinism', Journal of Public Policy, doi: 10.1017/S0143814X17000150.

Collins, R. (2000) 'Situational Stratification: A Micro-Macro Theory of Inequality', Sociological Theory 18(1): 17-43.

de Koster, W., Achterberg, P. and van der Waal, J. (2013) 'The new right and the welfare state: The electoral relevance of welfare chauvinism and welfare populism in the Netherlands', International Political Science Review 34(1): 3-20.

Dixon, J.C. (2006) 'The ties that bind and those that don't: Toward reconciling group threat and contact theory of prejudice', Social Forces 84(4): 2179-2204.

Ferrera, M. (2016) 'The contentious politics of hospitality: Intra-EU mobility and social rights', European Law Journal 22(6): 791-805.

Ferrera, M. and Pellegata, A. (2017) 'Can economic and social Europe be reconciled? Citizen views on integration and solidarity', REScEU Working Paper Series, Milan: University of Milan.

Hainmueller, J. and Hopkins, D.J. (2014) 'Public attitudes toward immigration', Annual Review of Political Science 17: 225-49.

Heindlmaier, A. and Blauberger, M. (2017) 'Enter at your own risk: free movement of EU citizens in practice’, West European Politics 40(6): 1198-1217.

Hjort, F. (2016) 'Who benefits? Welfare chauvinism and national stereotypes', European Union Politics 17(1): 3-24.

Houtman, D. (2003) 'Lipset and ‘working-class’ authoritarianism', American Sociologist 34: 86-105. 
Jacobs, F. (1992) ‘Opinion of Advocate General Jacobs’, delivered on December 1992, Case 168/91, available at:

http://curia.europa.eu/juris/showPdf.jsf;jsessionid=9ea7d2dc30d69aadb6102f4a410ea9 dbb797bc24b835.e34KaxiLc3qMb40Rch0SaxyMbhz0?text=\&docid=97983\&pageInd

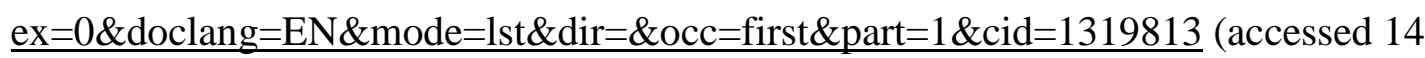
May 2018).

Karreth, J., Singh, S.P. and Stojek, S.M. (2015) 'Explaining attitudes toward immigration: The role of regional context and individual predispositions', West European Politics 38(6): 1174-1202.

Kitschelt, H. (1997) The Radical Right in Western Europe, Ann Arbor: University of Michigan Press.

Kramer, D., van Hooren, F. and Thierry, J. S. (2018) 'Responding to free movement: Quarantining mobile Union citizens in European welfare states’, Journal of European Public Policy <THIS ISSUE: PUBLISHER TO ADD /UPDATE DETAILS AT PROOF>

Kriesi, H. et al. (2008) West European Politics in the Age of Globalization, Cambridge: Cambridge University Press.

Kriesi, H. et al. (2012) Political Conflict in Western Europe, Cambridge: Cambridge University Press.

Kuhn, T. (2015) Experiencing European Integration. Transnational Lives and European Identity, Oxford: Oxford University Press.

Laurence, J. (2014) 'Reconciling the contact and threat hypotheses: Does ethnic diversity strengthen or weaken community inter-ethnic relations?', Ethnic and Racial Studies 37(8): 1328-1349.

Maas, C.J.M. and Hox, J.H. (2005) 'Sufficient Sample Sizes for Multilevel Modelling', 
Methodology 1: 86-92.

Marino, S., Penninx, R. and Roosblad, J. (2015) 'Trade unions, immigration and immigrants in Europe revisited Unions' attitudes and actions under new conditions', Comparative Migration Studies 3(1): 1-16.

Martínez-Lucio, M, Marino, S. and Connolly, H. (2013) 'Broadening and reimagining regulation: Trade unions, 'active servicing' and immigration in Spain since the early 1990s', The Journal of Industrial Relations 55(2): 190-211.

Mau, S. (2010) Social Transnationalism: Lifeworld beyond the Nation-State, London: Routledge.

McLaren, L. and Johnson, M. (2007) 'Resources, group conflict and symbols: Explaining anti-immigration hostility in Britain’, Political Studies 55(4): 709-732.

Mewes, J. and Mau, S. (2012) 'Unravelling working-class welfare chauvinism', in S. Svallfors (ed.) Contested Welfare States. Welfare attitudes in Europe and beyond, Stanford: Stanford University Press, pp. 119-157.

Pettigrew, T.F. (1998) ‘Intergroup contact theory’, Annual Review of Psychology 49: 65-85.

Pettigrew, T.F. (2016) 'In pursuit of three theories: Authoritarianism, relative deprivation, and intergroup contact, Annual Review of Psychology 67: 1-21.

Pottie-Sherman, Y. and Wilkes, R. (2017) 'Does size really matter? On the relationship between immigrant group size and anti-immigrant prejudice’, International Migration Review 51(1): 218-250.

Rauthmann, J.F., Sherman, R. and Funder, D.C. (Eds.) (2017) The Oxford Handbook of Psychological Situations, Oxford: Oxford University Press.

Recchi, E. (2015), Mobile Europe. The Theory and Practice of Free movement in the EU, London: Palgrave.

Reeskens, T., van Oorschot, W. (2012) 'Disentangling the 'new liberal dilemma': On the 
relation between general welfare redistribution preferences and welfare chauvinism', International Journal of Comparative Sociology 53(2): 120-13.

Riek, B., Mania, E. and Gaertner, L. (2006) 'Intergroup threat and outgroup attitudes: A metaanalytic review', Personality and Social Psychology Review 10(4): 336-353.

Schmidt, S. K., Blauberger, M., and Martinsen, D. S. (2018) 'Free movement and equal treatment in an unequal Union', Journal of European Public Policy <THIS ISSUE: PUBLISHER TO ADD /UPDATE DETAILS AT PROOF>.

Stephan, W.G., Ybarra, O. and Rios Morrison, K. (2009) 'Intergroup threat theory', in T. Nelson (ed.) Handbook of Prejudice, Stereotyping and Discrimination, Mahawah, N.J.: Lawrence Erlbaum Associates, pp.43-59.

Svallfors, S. (Ed.) (2012) Contested Welfare States: Welfare Attitudes in Europe and Beyond, Stanford: Stanford University Press.

Teney, C., Lacewell, O.P. and De Wilde, P. (2014) 'Winners and losers of globalization in Europe: attitudes and ideologies', European Political Science Review 6(4): 575-595.

van Der Waal, J., Achterberg, P., Houtman, D., de Koster, W. and Manevsk, K. (2010) “'Some are more equal than others': Economic egalitarianism and welfare chauvinism in the Netherlands', Journal of European Social Policy 20(4): 350-363.

van Oorschot, W. (2007) 'Solidarity towards immigrants in European welfare states', International Journal of Social Welfare 17: 3-14. 


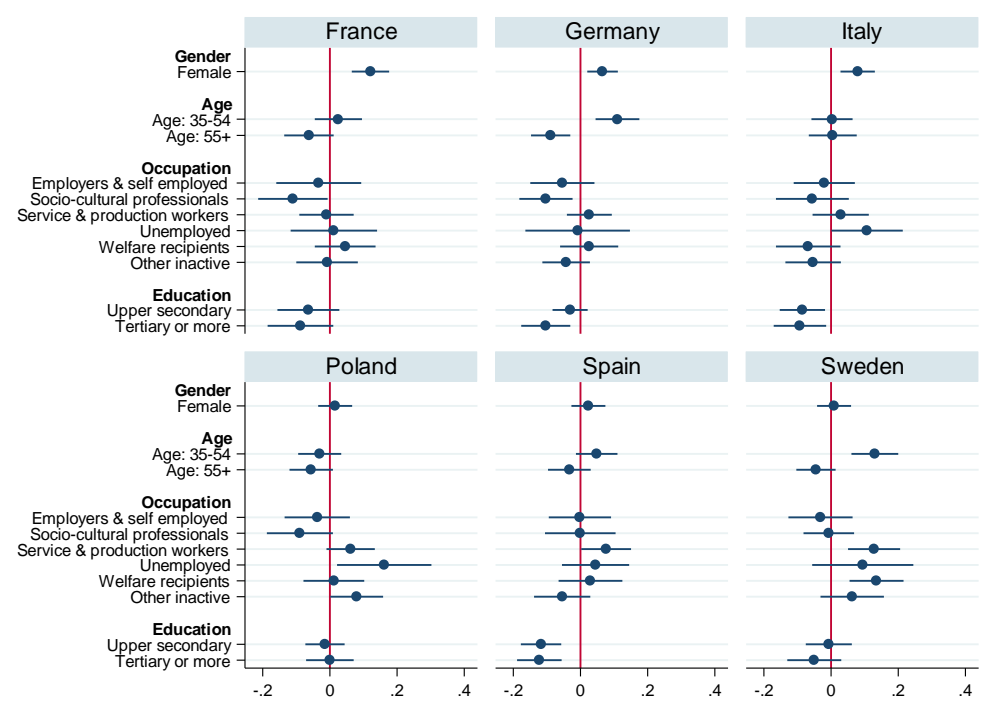

Figure 1. Difference in predicted probabilities of preferences for chauvinism at changing structural positions by country.

Notes: Graphs obtained from Model 1 in Tables A2-A7. 95\% confidence intervals are estimated. Reference categories: DV = freely and individually; Gender = male; Age = 18-34; Occupation = salaried middle class; Education = lower secondary or less. Source: REScEU Mass Survey.

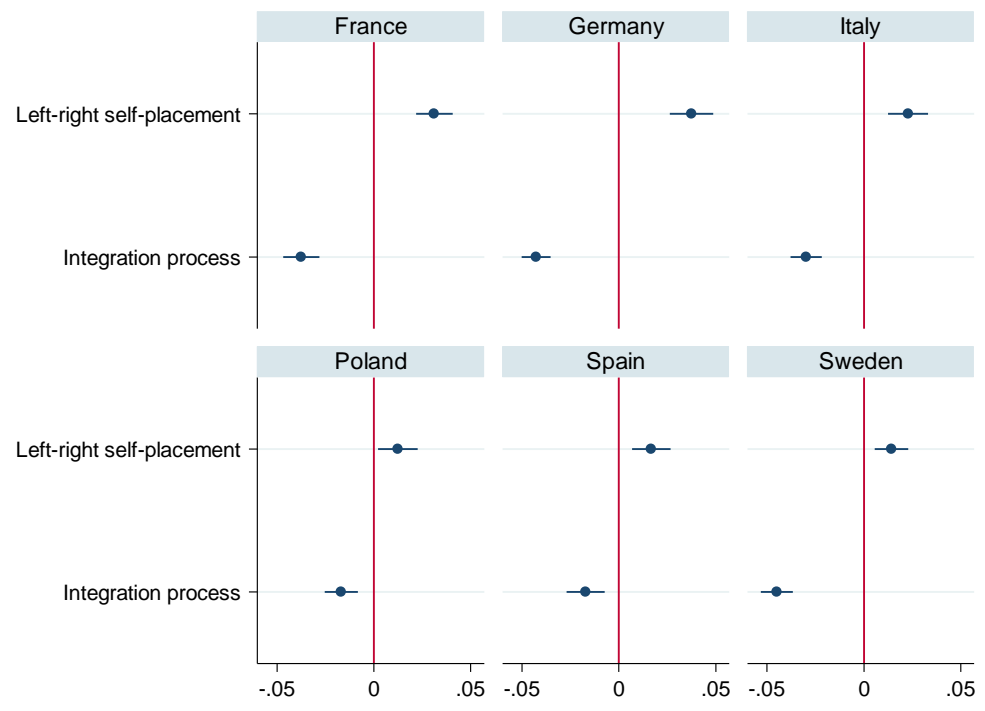

Figure 2. Difference in predicted probabilities of preferences for chauvinism at one-unit changes on political orientations scale by country.

Notes: Graphs obtained from Model 2 in Tables A2-A7. 95\% confidence intervals are estimated. Reference categories: $\mathrm{DV}=$ freely and individually. Source: REScEU Mass 
Survey.

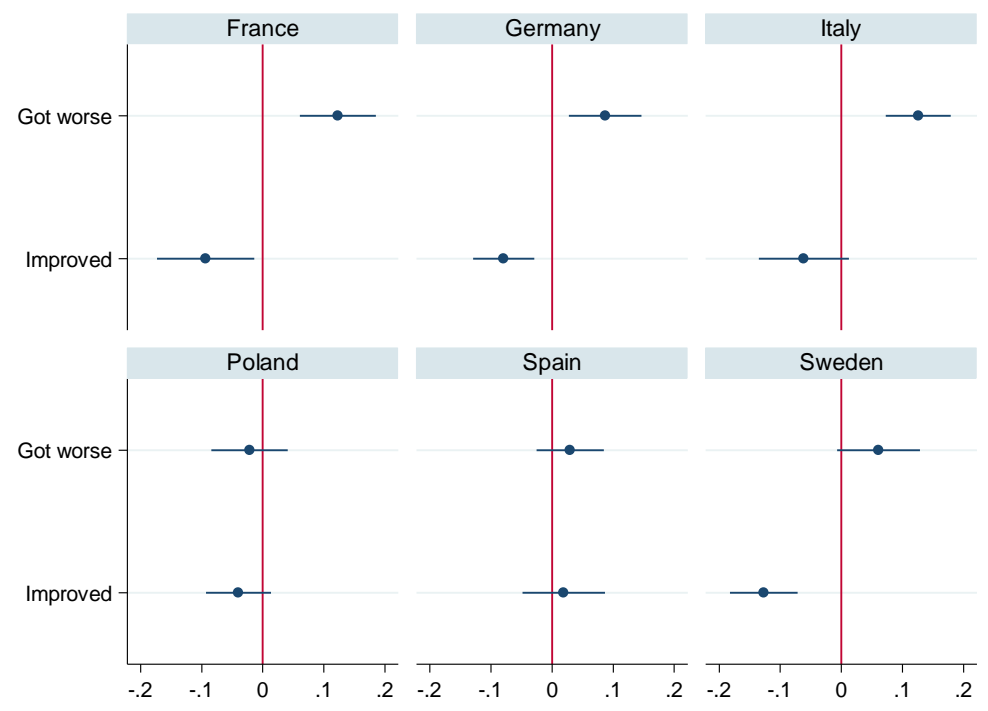

Figure 3. Difference in predicted probabilities of preferences for chauvinism at changing conditions of intertemporal material deprivation by country.

Notes: Graphs obtained from Model 3 in Tables A2-A7. 95\% confidence intervals are estimated. Reference categories: DV = freely and individually; Household financial situation = stayed about the same. Source: REScEU Mass Survey.

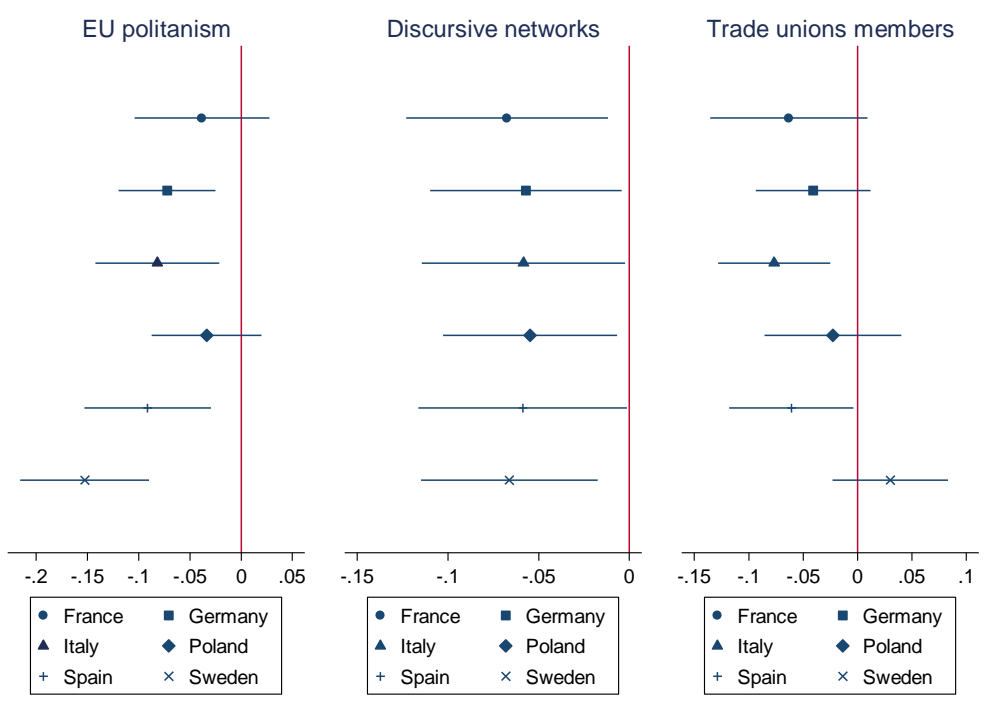

Figure 4. Difference in predicted probabilities of preferences for chauvinism at changing values of situational/relational factors by country.

Notes: Left-side graph obtained from Model 4, centre graph obtained from Model 5 and rightside graph obtained from Model 6. Models are taken from Tables A2-A7. 95\% confidence 
intervals are estimated. Reference categories: DV = freely and individually; EU-politanism = never visited another EU country; Discursive networks = no; Trade unions' member = no. Source: REScEU Mass Survey.

\footnotetext{
${ }^{1}$ We refer to the Online Appendix for a detailed presentation of the survey.

${ }^{2}$ Although the dependent variable can be considered an ordinal variable, given the peculiar nature of the second response category, we prefer to treat it as a nominal one. The second option can be understood as a 'partial opening' or a 'partial closure' on the side of EU workers, depending on whether it is contrasted to the first or to the third category. It was included in the survey to appropriately measure attitudes towards free-movement, especially in those countries (such as Germany) that experienced this kind of practice in the past, but it is much less relevant for the purpose of this study. Thus, although the tables presenting the empirical models also report results for the second response category, for the sake of the presentation we do not discuss them in the following section. However, even considering the dependent variable as an ordinal variable or dichotomising it by merging the second and the third response categories, the main results do not change.

${ }^{3}$ In France, this relationship is significant at $p<0.1$.
} 